\title{
PERFORMANCE OF TWIST-COUPLED BLADES ON VARIABLE SPEED ROTORS
}

\author{
Don.W. Lobitz, Principle Member of the Technical Staff \\ 505-844-9398/dwlobit@sandia.gov \\ Paul S. Veers, Distinguished Member of the Technical Staff \\ 505-844-5522/psveers@sandia.gov \\ Sandia National Laboratories \\ Albuquerque, New Mexico 87185 \\ David J. Laino \\ 801-278-7852/dlaino@windwardengineering.com
}

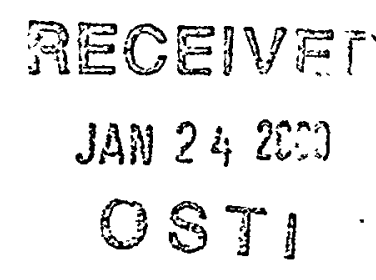

Windward Engineering

Salt Lake City, Utah 84117

\begin{abstract}
The load mitigation and energy capture characteristics of twist-coupled HAWT blades that are mounted on a variable speed rotor are investigated in this paper. These blades are designed to twist toward feather as they bend with the pretwist set to achieve a desirable twist distribution at rated power. For this investigation, the ADAMS-WT software has been modified to include blade models with bending-twist coupling. Using twistcoupled and uncoupled models, the ADAMS software is exercised for steady wind environments to generate $C_{p}$ curves at a number of operating speeds to compare the efficiencies of the two models. The ADAMS software is also used to generate the response of a twist-coupled variable speed rotor to a spectrum of stochastic wind time series. This spectrum contains time series with two mean wind speeds at two turbulence levels. Power control is achieved by imposing a reactive torque on the low speed shaft proportional to the RPM squared with the coefficient specified so that the rotor operates at peak efficiency in the linear aerodynamic range, and by limiting the maximum RPM to take advantage of the stall controlled nature of the rotor. Fatigue calculations are done for the generated load histories using a range of material exponents that represent materials from welded steel to aluminum to composites, and results are compared with the damage computed for the rotor without twist-coupling. Power output for the various cases is also monitored to determine power deviations resulting from the coupling. Results indicate that significant reductions in damage are achieved across the spectrum of applied wind loading without any degradation in power production.
\end{abstract}

This work was supported by the United States Department of Energy under Contract DE-AC04-94AL8500.

This material is declared a work of the U. S. Government and is not subject to copyright protection in the United States.
A fairly comprehensive literature survey for blades which are designed to deform in some desired way under the action of aerodynamic and centrifugal.loads is presented in Reference 1. Some of the references cited in that work which include both wind turbine and helicopter applications are reproduced in the Appendix. The prospect of installing blades that twist as they bend and/or extend on horizontal axis wind turbines provides opportunities for enhanced energy capture and/or load mitigation. Although this coupling could be achieved in either an active or passive manner, the passive approach is much more attractive due to its simplicity and economy. As an example, a blade design might employ coupling between bending and twisting so that, as the blade bends due to the action of the aerodynamic loads, it also twists modifying the aerodynamic performance in some way.

Previous works have focused on the application of blades with this bending-twist coupling to constant speed rotors, investigating increased energy capture, aeroelastic stability, and enhanced load mitigation. Results indicate that energy capture can be increased significantly by configuring the coupled blades to twist toward stall while increasing the rotor diameter to maintain the maximum power at its design value ${ }^{2}$. However subsequent simulations with the rotor turning in turbulent winds show substantial increases in fatigue damage when the coupled blades (i.e. blades with bending-twist coupling) twist toward stall as they bend ${ }^{4}$. Moreover for a range of windspeeds in the stall regime stall flutter is observed ${ }^{4}$. Twisting toward stall also destabilizes divergence although not critically for reasonable levels of coupling ${ }^{3}$. In contrast, when the blades twist toward feather, fatigue damage is reduced by approximately a factor of two, stall flutter is not observed and divergence is stabilized ${ }^{3,4}$. Classical flutter, however, is destabilized, although not critically for reasonable levels of 


\section{DISCLAIMER}

This report was prepared as an account of work sponsored by an agency of the United States Government. Neither the United States Government nor any agency thereof, nor any of their employees, make any warranty, express or implied, or assumes any legal liability or responsibility for the accuracy, completeness, or usefulness of any information, apparatus, product, or process disclosed, or represents that its use would not infringe privately owned rights. Reference herein to any specific commercial product, process, or service by trade name, trademark, manufacturer, or otherwise does not necessarily constitute or imply its endorsement, recommendation, or favoring by the United States Government or any agency thereof. The views and opinions of authors expressed herein do not necessarily state or reflect those of the United States Government or any agency thereof. 


\section{DISCLAIMER}

Portions of this document may be illegible in electronic image products. Images are produced from the best available original document. 
coupling ${ }^{3}$. There is evidence from the simulated power curve of a constant speed rotor that energy capture may be somewhat reduced when the blades twist toward feather ${ }^{4}$. It should be noted that these blades were originally designed to operate without the twist-coupled feature and were pitched as a rigid body toward stall to limit the maximum power to its design value. However, twist-coupled blades carefully designed to eliminate this preset pitch would tend to minimize this reduction and possibly even increase performance in low winds. Active turbine power control also serves to eliminate this degradation.

As with the previous work, the analysis for the bendingtwist coupled blade is carried out within the confines of beam finite element theory using the $\mathrm{ADAMS}^{5}$ software. The coupling terms for the beam elements are generated starting with beam "stress-strain" relations. For the bending-twist coupling the "stress-strain" relations at a point along the blade span, $x$, are given by:

$$
\left[\begin{array}{cc}
E I & -g \\
-g & G K
\end{array}\right]\left[\begin{array}{l}
\frac{\partial \theta}{\partial x} \\
\frac{\partial \varphi}{\partial x}
\end{array}\right]=\left[\begin{array}{c}
M_{b} \\
M_{t}
\end{array}\right]
$$

Here, $\theta=\partial \nu / \partial x$ is the flapwise slope of the blade ( $v$ is the flapwise displacement), $M_{b}$ is the flapwise bending moment, $\varphi$ is the blade twist, and $M_{t}$ is the twisting moment. The quantities $E I$ and $G K$ are the flexural rigidity and torsional stiffness respectively, and $g$ is the coupling term which has a value of zero for the standard beam where no coupling is present. In order for this system to be positive definite $g$ is taken to be:

$$
g=\alpha \sqrt{E I G K}, \quad-1<\alpha<1
$$

The coupling coefficient, $\alpha$, provides for variable coupling within the designated limits. Practical experience ${ }^{6}$ suggests that $\alpha$ may be limited to $-0.6<\alpha<0.6$. Only bending in the flapwise direction is accounted for in Equation 1. Bending in the edgewise direction is considered to be small relative to the flapwise direction; yielding minimal coupling: Axial extension is also ignored for this type of coupling. For ease of model generation the ADAMS-WT ${ }^{7}$ software is modified to incorporate the bending-twist coupling.

The current work focuses on the application of bendingtwist coupled blades to a variable speed controlled rotor. These blades are first optimized by setting the pretwist such that a desirable twist distribution is achieved at. rated power. For steady wind operation, the peak rotor efficiency is determined at each windspeed by optimally adjusting the rotor RPM. This peak efficiency is plotted versus wind speed and compared to that for blades with no twist-coupling. Simulations are also completed for turbulent winds, to verify that the reductions in fatigue damage noted for constant speed operation are also evident for the variable speed case, and to investigate any possible power degradation. :

Using a twist-coupled model of a representative variable speed rotor, ADAMS is exercised using turbulent wind time series generated with SNLWIND- $3 D^{8}$ for hubheight mean windspeeds of $8 \mathrm{~m} / \mathrm{s}$ and $14 \mathrm{~m} / \mathrm{s}$, each approximately 90 minutes in length. These windspeeds represent the linear aerodynamic and stall regions of the power curve, respectively. The post stall region of the power curve was not investigated here because in that region the rotor is operating at a constant speed, a configuration previously addressed ${ }^{4}$. Two turbulence levels are used in these simulations, the current IEC Class I standard ${ }^{9}$ and $50 \%$ of that standard. These levels represent a relatively turbulent site and a relatively benign one. With the wind loadings defined above, computations are completed for blades with the optimal pretwist and a value of the bending-twist coupling coefficient of $\alpha=0.6$, where $\alpha=0.0$ corresponds to the uncoupled case. Load histories and power output are computed and stored for all of the above cases for subsequent posit processing.

Fatigue damage estimates are computed for these load histories assuming that damage is proportional to the load cycle amplitude raised to a material exponent, $b$, namely:

$$
D \propto S^{b}
$$

where $S$ is the stress amplitude and $D$ is fatigue damage.

Values for $b$ of 3,6, and 9 are used to represent a range of materials from welded steel to aluminum to composites. The damage is assumed to be cumulative and therefor Miner's Rule is invoked. Damage results for the selected level of bending-twist coupling are compared to the uncoupled case. Average power levels are also compared.

The remaining sections of the paper contain a description of the rotor model and wind inputs, computed results, and concluding remarks.

\section{ROTOR AND TURBULENCE MODELS}

The rotor models created using ADAMS-WT employ fully flexible blades comprised of 20 elements each. All other model parts and interconnections are rigid. 
Table 1: Model Configuration Summary

\begin{tabular}{|l|l|}
\hline \multicolumn{1}{|c|}{ Parameter } & \multicolumn{1}{c|}{ Value } \\
\hline \hline Number of blades & 3 \\
\hline Rotor configuration & upwind \\
\hline Yaw configuration & fixed \\
\hline Blade length & $14.9 \mathrm{~m}$ \\
\hline Rotor hub radius & $1.5 \mathrm{~m}$ \\
\hline Rotor precone angle & $0.0 \mathrm{deg}$ \\
\hline Rotor radius & $16.4 \mathrm{~m}$ \\
\hline Rotor hub height & $50 \mathrm{~m}$ \\
\hline Rotor tilt angle & $0.0 \mathrm{deg}$ \\
\hline Sling (dist from yaw axis to hub) & $4.0 \mathrm{~m}$ \\
\hline Rotor rotational speed (variable) & $0-32 \mathrm{RPM}$ \\
\hline
\end{tabular}

Parameters for the basic model are presented in Table 1. The rotor blade is based on an existing $15 \mathrm{~m}$ blade design, modified to include twist-coupling. Models were developed for coupling coefficients of $\alpha=0.6$ and $\alpha=0.0$. For the uncoupled case the pretwist varies as indicated in Figure 1 by the solid curve (the negative sign indicating twist toward feather). For the twist-coupled rotor the pretwist was set so that this twist distribution was achieved at rated power.

This pretwist is determined by building a rotor with two blades in the same azimuthal location, one uncoupled and one with twist-coupling. Pointers in the ADAMS/

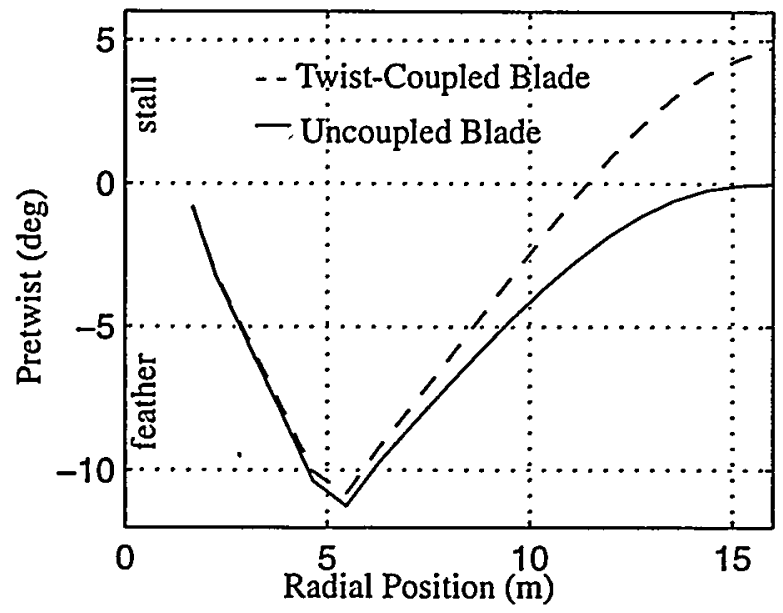

Figure 1: Pretwist for the twist-coupled and uncoupled blades.
Solver dataset are then modified so that aeroloads from AERODYN ${ }^{10}$ computed for the uncoupled blade were also applied to the coupled one (in lieu of the aeroloads AERODYN would normally compute for it). The blade twist distribution that occurs due to the twist-coupling under this loading is then subtracted from the desired twist distribution providing the optimal pretwist. Thus when the aeroelastic twists are included in the aeroload computations the twist distribution at the rated power will coincide with the desired one. The accuracy of this technique depends on the linearity of the blade twist with the aeroloads in the range of interest.

For the rotor turning at 32 RPM the windspeed at rated power was defined to be $13 \mathrm{~m} / \mathrm{s}$. This value was chosen in part to bring the peak power of the twist-coupled rotor into compliance with that of the uncoupled one. The optimal pretwist for the twist-coupled blade under the load associated with this windspeed is shown in Figure 1 by the dashed curve. To be more consistent with convention, this pretwist could be recast by shifting the distribution so that the pretwist is zero at the tip and then specifying a full blade pitch of 4.85 degrees toward stall. The power curves for the coupled with optimal pretwist and uncoupled rotors operating at a constant speed of 32 RPM are shown in Figure 2. Note that the two power curves are essentially equivalent with the uncoupled rotor generating slightly more power than the twist-coupled one at the extremes of the windspeed range.

Variable speed control was effected by applying a reactive torque to the rotor at the low speed shaft. For the linear aerodynamics range of the power curve this torque was made proportional to the RPM squared with the coefficient selected to balance the torque produced

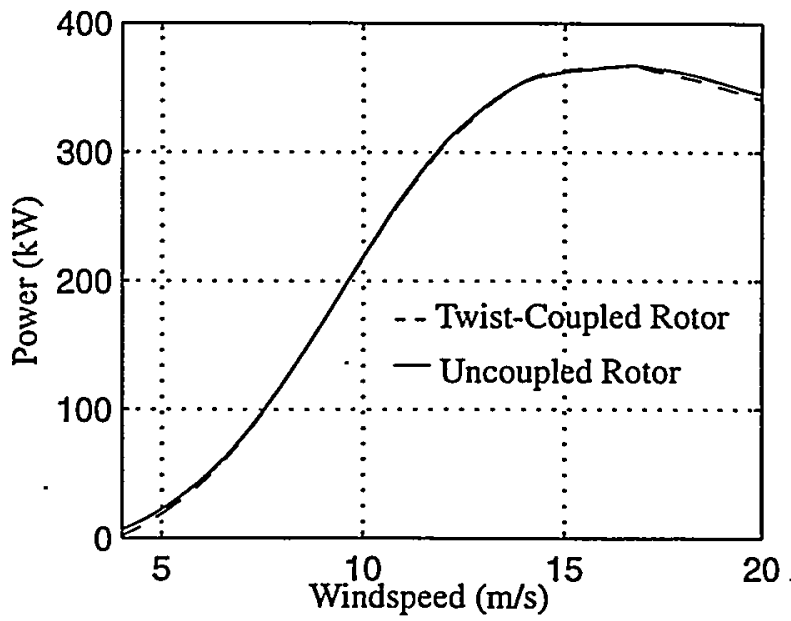

Figure 2: Power curves for the uncoupled rotor and the twist-coupled one with optimal pretwist. 
by the wind loads, thereby allowing the rotor to operate at maximum efficiency. Above the linear range, the stall controlled nature of the rotor was exploited by limiting the rotor speed to 32 RPM. This was accomplished by significantly increasing the reactive torque when this RPM is exceeded. The coefficient for the torque equation in the linear range was computed using data from the peak of the $C_{p}$ curve for the uncoupled rotor. This coefficient was also used for the twist-coupled rotor although it may not be optimal. The tip speed ratio at this peak value combined with the maximum rotor speed indicate that the wind speed at the top of the linear range is approximately $8.6 \mathrm{~m} / \mathrm{s}$.

Simulated turbulence was created using SNLWIND-3D for 2 average wind speeds as discussed earlier. Inputs to the program were chosen to duplicate conditions specified in the IEC standard. Shear velocity input was used to vary turbulence intensity. Nine 10-minute wind data sets, each with a different seed, were created at each wind speed for IEC turbulence intensity levels. Nine additional 10-minute turbulence files were created at each wind speed with the turbulence intensity set to $50 \%$ of IEC levels. Generally turbulence intensities for the simulated winds at 8 and $14 \mathrm{~m} / \mathrm{s}$ came out slightly less than the target values.

In all, a total of 90 minutes of simulated turbulence at each mean wind speed and turbulence level were created. Thus, with the two models investigated, a total of 720 simulated minutes - comprised of 72 10-minute simulations - are used in this analysis.

\section{RESULTS}

Steady Wind Results for a Twist-Coupled Rotor

For an uncoupled variable speed rotor, the efficiency of the rotor in the linear aerodynamic range can be maximized by running at the tip speed ratio associated with the peak of the power coefficient curve. For the twistcoupled case, however, the location of the peak of the power coefficient curve changes modestly with rotor RPM due to the twisting of the blades. Thus the maximum rotor efficiency must be represented as a function of windspeed (or RPM) and the RPM versus windspeed schedule required to achieve maximum efficiency must be altered from that of the uncoupled rotor.

Using the ADAMS software for both the twist-coupled and uncoupled rotors, power curves were generated for rotor speeds from 12 to $36 \mathrm{RPM}$ in intervals of $3 \mathrm{RPM}$ for windspeeds varying from 4 to $20 \mathrm{~m} / \mathrm{s}$. The families of $C_{p}$ curves shown in Figure 3 were developed from these power curves. For the uncoupled rotor these

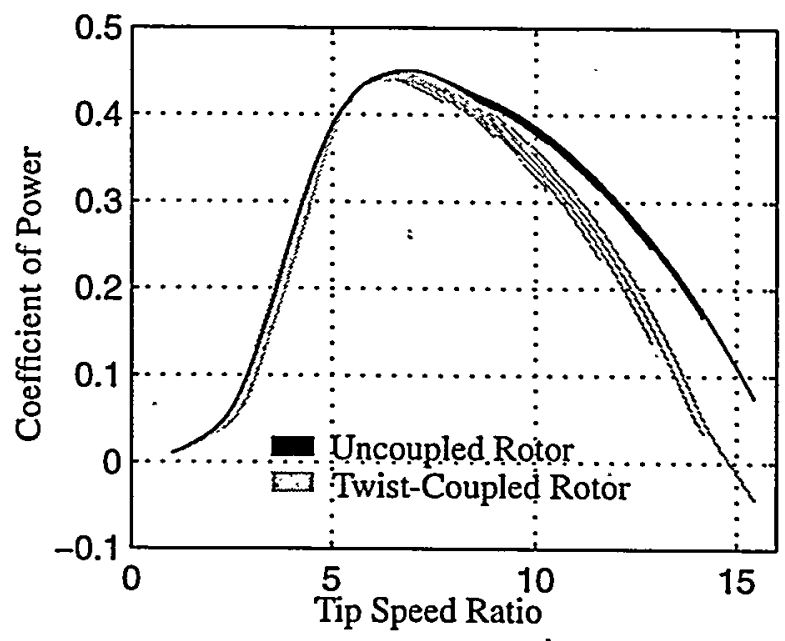

Figure 3: $C_{p}$ curve families for rotor speeds from 12 to 36 RPM for the twist-coupled and uncoupled rotors.

curves are nearly coincident as expected, but for the twist-coupled one there is some degree of spread due to the induced blade twisting. Plots of the maximum efficiency versus windspeed shown in Figure 4 were also developed from the power curves. It is apparent from these curves that over a significant portion of the windspeed range associated with linear aerodynamics, the maximum rotor efficiencies are essentially identical. At lower windspeeds the uncoupled rotor operates at modestly higher efficiencies than the twist-coupled one. The RPM versus windspeed schedules required to achieve these efficiencies are shown in Figure 5. Note that the schedule for the uncoupled rotor is approximately linear with windspeed, representing a constant tip speed ratio. The $C_{p}$ curves of Figure 3 indicate that those for the twist-coupled rotor tend to have sharper peaks than those for the uncoupled rotor. This may make it more difficult for the twist-coupled rotor to achieve maximum

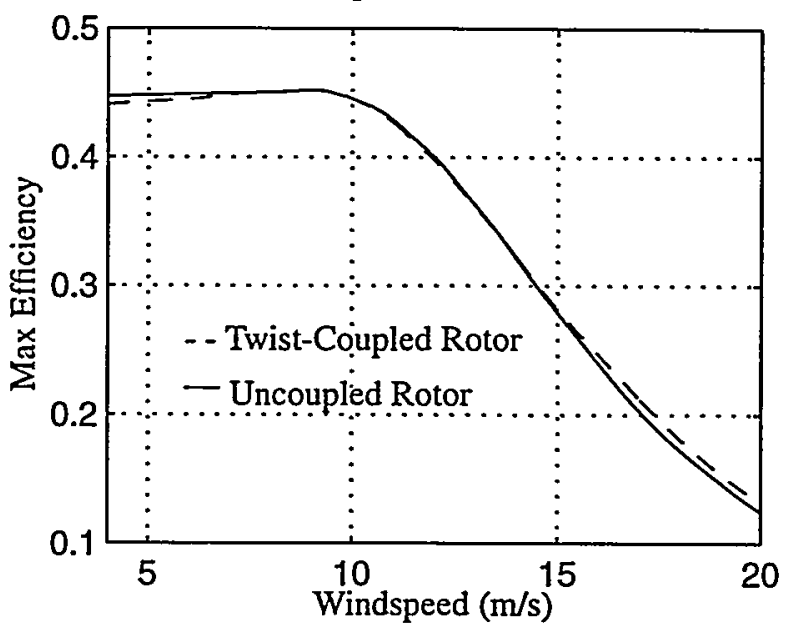

Figure 4: Comparison of the efficiencies of the twist-coupled and uncoupled rotors. 


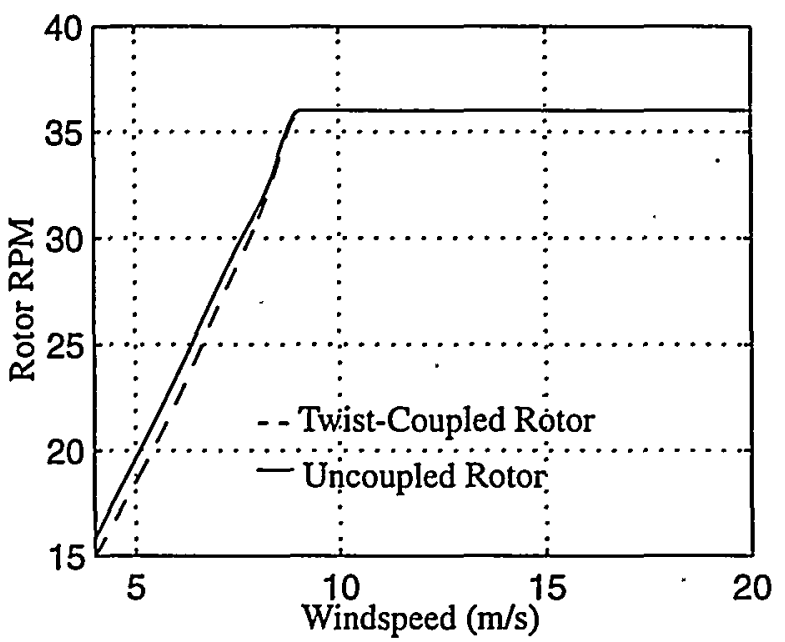

Figure 5: Comparison of the max efficiency RPM schedules for the twist-coupled and uncoupled rotors.

efficiency in a turbulent wind environment, resulting in reduced energy capture. This issue will be investigated in the next segment of this section

\section{Turbulent Wind Results for a Twist-Coupled Rotor}

Simulation results discussed in this segment include normalized fatigue damage and average power for the uncoupled and twist-coupled variable speed rotors driven by the various turbulent wind loadings.

The fatigue damage is computed for the out-of-plane root bending moment only as the loads are generally highest for that moment at that location. Loads due to blade twist are not considered in the damage computation. Figure 6. summarizes the fatigue damage results. For each turbulence intensity the damage for both rotors is normalized to the damage accumulated by the uncoupled rotor for the $14 \mathrm{~m} / \mathrm{s}$ wind. Thus in Figures $6 \mathrm{c}$ and $6 \mathrm{~d}$ the damage associated with the uncoupled rotor is unity for all three values of the material exponent.

For the $8 \mathrm{~m} / \mathrm{s}$ windspeed both rotors are operating in a variable speed mode the majority of the time since the windspeed at the top of the linear range is approximately $8.6 \mathrm{~m} / \mathrm{s}$. Comparing damage results for this windspeed at the two turbulence intensity levels (Figures $6 \mathrm{a}$ and $6 \mathrm{~b}$ ), there is significant damage reduction for the twist-coupled rotor relative to the uncoupled one especially for the higher material exponents. When $b=3$, the damage reduction is minimal.

Figures $6 \mathrm{a}$ and $6 \mathrm{~b}$ when compared to Figures $6 \mathrm{c}$ and $6 \mathrm{~d}$ show the curious result that the relative damage for an $8 \mathrm{~m} / \mathrm{s}$ wind at $b=6$ and 9 is greater than that at $14 \mathrm{~m} / \mathrm{s}$. As discussed by Lobitz and Laino ${ }^{4}$, this is due to differ-

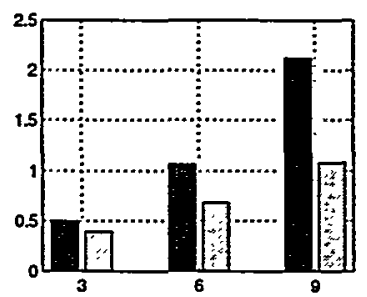

a) $8 \mathrm{~m} / \mathrm{s}, 100 \%$ turb.

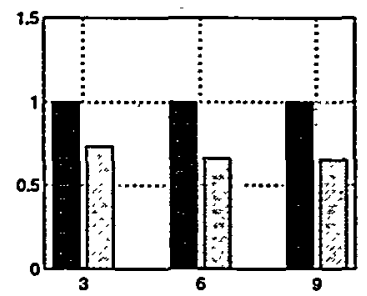

c) $14 \mathrm{~m} / \mathrm{s}, 100 \%$ turb.

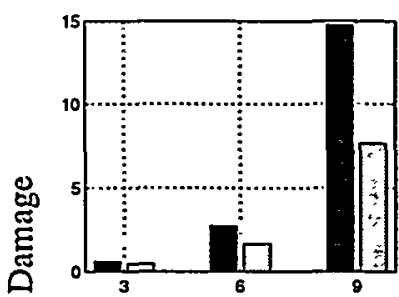

b) $8 \mathrm{~m} / \mathrm{s}, 50 \%$ turb.

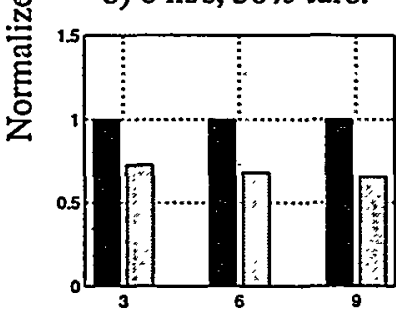

d) $14 \mathrm{~m} / \mathrm{s}, 50 \%$ turb.
Material Exponent " $b$ "

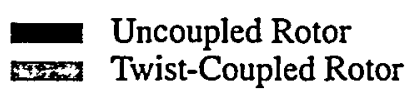

Figure 6: Comparison of relative fatigue damage for

a) $8 \mathrm{~m} / \mathrm{s}$ winds with $100 \%$ IEC turbulence intensity.

b) $8 \mathrm{~m} / \mathrm{s}$ winds with $50 \%$ IEC turbulence intensity.

c) $14 \mathrm{~m} / \mathrm{s}$ winds with $100 \%$ IEC turbulence intensity.

d) $14 \mathrm{~m} / \mathrm{s}$ winds with $50 \%$ IEC turbulence intensity.

ences in range of lift coefficient that occurs at different windspeeds and turbulence levels. Thus although the mean loads are greater at $14 \mathrm{~m} / \mathrm{s}$ the load cycle ranges may be greater at $8 \mathrm{~m} / \mathrm{s}$.

This is illustrated in Figure 7 where inverse Weibull distributions (i.e. $\ln (-\ln (1-C D F))$, where $C D F$ is the Cumulative Distribution Function) are shown for the rotor load ranges associated with the two turbulence levels. The inverse Weibull is a probability scale. So each horizontal level is associated with a specific probability. With this in mind, the right-most curves at a given probability level represent configurations which possess greater load ranges. The logarithmic nature of these curves tends to dwarf results, and therefore differences between the solid and dashed curves are actually greater than they appear. In any case the dashed curves of Figure 7 corresponding to the uncoupled rotor tend to lie to the right of the solid ones which represent the twist-coupled rotor, indicating greater load ranges and therefor greater damage for the uncoupled rotor. For both turbulence levels the $8 \mathrm{~m} / \mathrm{s}$ curves cross over the $14 \mathrm{~m} / \mathrm{s}$ ones such that higher load ranges are more prevalent for the 8 $\mathrm{m} / \mathrm{s}$ case. When these load ranges are raised to the powers of 6 and 9 they contribute substantially to the damage, and result in a greater cumulative damage for the 8 $\mathrm{m} / \mathrm{s}$ wind relative to the $14 \mathrm{~m} / \mathrm{s}$ one.

For the windspeed of $14 \mathrm{~m} / \mathrm{s}$, both rotors are operating 

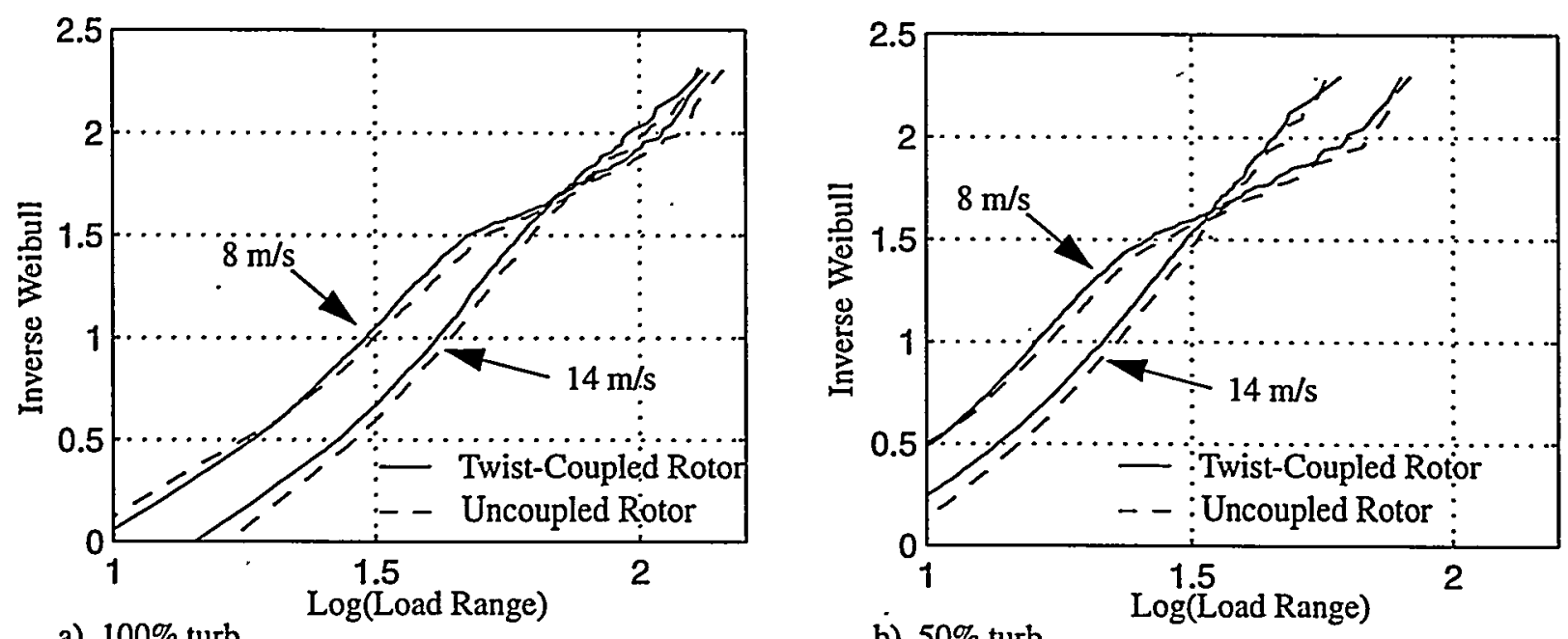

a) $100 \%$ turb.

b) $50 \%$ turb.

Figure 7: Inverse Weibull plots of the rotor load range distributions for

a) $100 \%$ IEC turbulence intensity.

b) $50 \%$ IEC turbulence intensity.

in the stall regime and therefore turn at a nearly constant speed of 32 RPM. For the two turbulence intensities the normalized damage is shown in Figures $6 c$ and $6 d$. Damage reductions for the twist-coupled blade relative to the uncoupled one are substantial, even at $b=3$ where reductions are minimal for the $8 \mathrm{~m} / \mathrm{s}$ windspeed.

The damage results for $14 \mathrm{~m} / \mathrm{s}$ are similar to those reported in Reference 4 where the rotors operated at constant speed. Some deviation is expected due to the different ways in which the twist-coupled blade is configured to limit peak power (twist scheduling versus preset full blade pitch). However, comparing Figures $6 \mathrm{c}$ and $6 \mathrm{~d}$ with their counterparts in Reference 4, the damage reductions there are approximately $50 \%$ greater than those reported here. The probable cause of this difference is that the authors of that document unwittingly specified a twist coupling coefficient of approximately

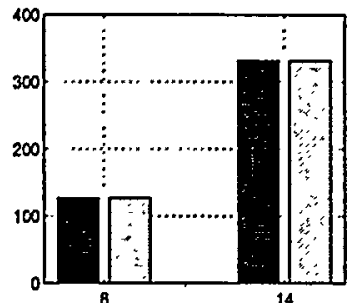

a) $100 \%$ turb.

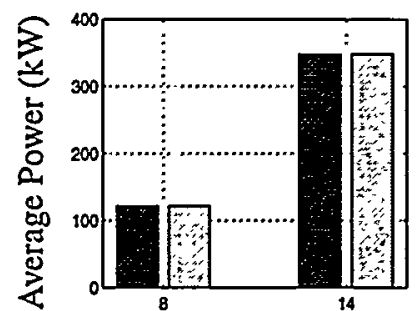

b) $50 \%$ turb.
Windspeed $(\mathrm{m} / \mathrm{s})$

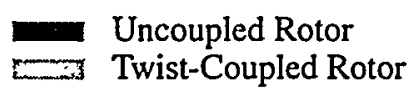

Figure 8: Comparison of average power for 8 and 14 $\mathrm{m} / \mathrm{s}$ winds with

a) $100 \%$ IEC turbulence intensity.

b) $50 \%$ IEC turbulence intensity. $\alpha=0.72$, whereas it was thought and reported to be 0.6 , and generally the greater the twist coupling coefficient the greater the damage reduction.

In Figure 8 comparisons are shown for average power for the twist-coupled and original uncoupled (the stiffer one) rotors at the two turbulence levels. As indicated, differences in power output between the uncoupled and twist-coupled rotors are negligible.

\section{Turbulent Wind Results for a Softened Rotor}

In References 3 and 6 mathematical expressions are presented indicating that the introduction of off diagonal terms in the beam stiffness matrix to model twist-coupling causes the beam to become softer in bending, even though the terms representing the flexural rigidity are not altered. This softening is also apparent in the current simulations where blade tip deflections for the twist-coupled rotor exceed those of the uncoupled one by approximately $50 \%$, as shown in the histograms of Figure 9 for the $14 \mathrm{~m} / \mathrm{s}$ windspeed at $100 \%$ IEC turbulence intensity. To determine the role this softening plays in the damage reduction an additional uncoupled model was developed where both the blade flexural rigidity and torsional stiffness were reduced to be commensurate with those of the twist-coupled model. Resulting blade tip deflections for this new model are equivalent to those of the twist-coupled one (see Figure 9). Fatigue damage comparisons for this new softer uncoupled model relative to the previous uncoupled one are shown in Figure 10 in a format similar to that of Figure 6 . The bar charts for the $8 \mathrm{~m} / \mathrm{s}$ windspeed show that there is indeed a damage reduction associated with the softer uncoupled model, although not as large as that of 


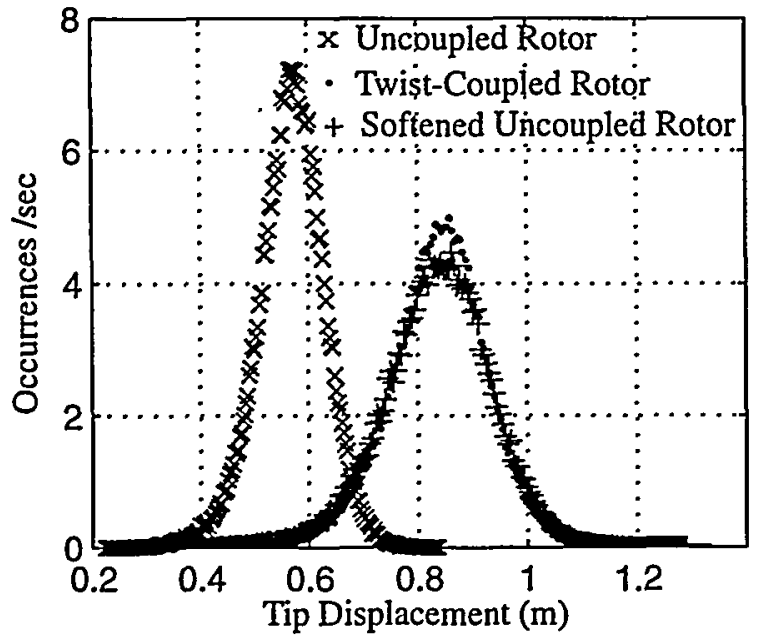

Figure 9: Histograms of tip displacements for the uncoupled, twist-coupled and softened uncoupled rotors $(14 \mathrm{~m} / \mathrm{s}, 100 \% \mathrm{IEC}$ turbulence intensity).

the twist-coupled rotor. For $14 \mathrm{~m} / \mathrm{s}$ windspeed the damage for the softer uncoupled rotor actually increases relative to the stiffer one. Thus just softening the blades produces mixed results with regard to fatigue damage reduction and at best provides only a fraction of the damage reduction produced when twist-coupling is incorporated.

\section{CONCLUSIONS AND RECOMMENDATIONS}

The ADAMS software is employed to investigate the feasibility of using HAWT blades that twist as they bend to mitigate fluctuating loads for a variable speed rotor. The twist coupling coefficient for the blades was set at $\alpha=0.6$ (twisting toward feather), and the blades were pretwisted toward stall to match the constant speed power curve for uncoupled blades. Power control is achieved by imposing a reactive torque on the low speed shaft proportional to the RPM squared with the coefficient specified so that the rotor operates at peak efficiency in the linear aerodynamic range, and by limiting the maximum RPM to take advantage of the stall controlled nature of the rotor.

Prior to running turbulent wind simulations, steady wind results were obtained showing that for variable speed operation the twist coupled rotor described above can be almost as efficient as the uncoupled one if a slightly altered RPM versus windspeed schedule is followed.

Turbulent wind simulations were made for two average hub-height wind speeds and two wind turbulence settings. Fatigue damage is computed from the load histories using material exponents that represent materials ranging from welded steel to composites. In most cases

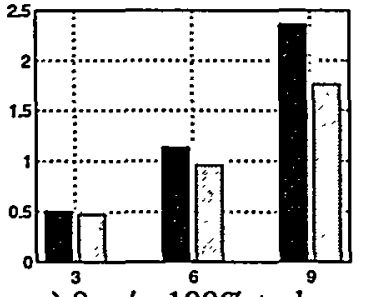

a) $8 \mathrm{~m} / \mathrm{s}, 100 \%$ turb.

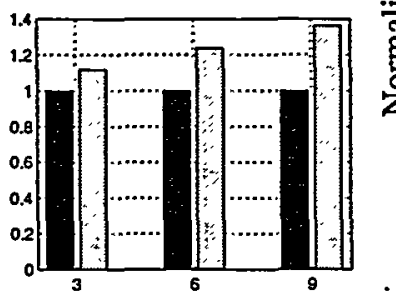

c) $14 \mathrm{~m} / \mathrm{s}, 100 \%$ turb.

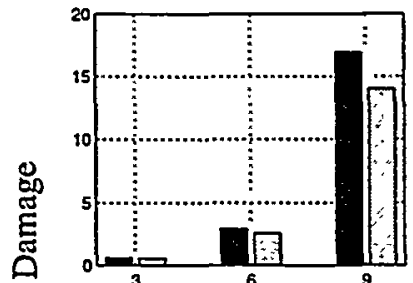

b) $8 \mathrm{~m} / \mathrm{s}, 50 \%$ turb.

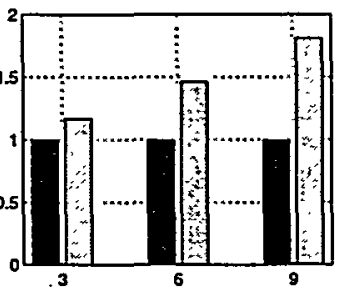

d) $14 \mathrm{~m} / \mathrm{s}, 50 \%$ turb.
Material Exponent " $b$ "

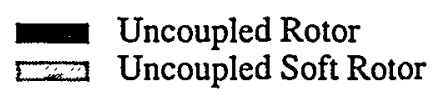

Figure 10: Comparison of relative fatigue damage for a) $8 \mathrm{~m} / \mathrm{s}$ winds with $100 \%$ IEC turbulence intensity.

b) $8 \mathrm{~m} / \mathrm{s}$ winds with $50 \%$ IEC turbulence intensity.

c) $14 \mathrm{~m} / \mathrm{s}$ winds with $100 \%$ IEC turbulence intensity.

d) $14 \mathrm{~m} / \mathrm{s}$ winds with $50 \%$ IEC turbulence intensity.

significant to substantial fatigue damage reductions (30-50\%) were exhibited by the twist-coupled rotor, with the exception that for the low windspeed with the material exponent set at 3 the damage reduction was minimal. In all cases power production for the twistcoupled rotor was equivalent to the uncoupled one. Thus for this twist-coupled rotor, substantial fatigue damage reductions prevail for the rotor in variable speed operation as in the case for constant speed, and with no loss in power output.

The turbine model used was a simple one, making it difficult to extrapolate results to machines incorporating pitch control which would extend the range for variable speed operation, free yaw, and/or non-zero rotor coning. The combination of rotor coning and variable speed is especially interesting, as twist will vary with rotor speed due to flap loading caused by centrifugal force. The substantial fatigue damage reductions that have been predicted call for additional study, and twist-coupled rotors incorporating these increasingly common characteristics should be investigated not only for load mitigation but also to determine the impact of twist coupling on various rotor control forces.

The fatigue benefits of twist-coupling can only be realized if blades incorporating this trait can be built. Composite, uniform, D-spars have already been designed and 
fabricated ${ }^{6}$ that possess coupling coefficients in the range of 0.6. The next step involves the design and fabrication of a much more complex twist-coupled blade with a coupling coefficient in this same range. Design factors such as span-wise variance of coupling coefficient, and optimization of blade geometry to make the most of the advantages of twist-coupling need to be investigated. The ultimate goal is to design and produce a rotor blade that provides maximum benefit to turbine performance with minimal additional production cost.

\section{ACKNOWLEDGEMENTS}

The authors wish to express their gratitude to Marshall Buhl for his assistance in getting the PC version of ADAMS up and running at Sandia, Craig Hansen for his guidance in developing a simple variable speed control system for stall controlled rotors, and Kirk Pierce for providing his control system for variable speed, pitch controlled rotors.

\section{APPENDIX}

A fairly comprehensive literature survey for blades which are designed to deform in some desired way under the action of aerodynamic and centrifugal loads is presented in Reference 1. Some of the references cited in that work which include both wind turbine and helicopter applications are reproduced below.

\section{Wind Turbine Applications}

Cheney, M. C. and Speirings, P. S. M. "Self Regulating Composite Bearingless Wind Turbine," Solar Energy, Vol. 20, (1978).

Bottrell, G. W. "Passive Cyclic Pitch Control for Horizontal Axis Wind Turbines," Proceedings of Wind Turbine Dynamics, NASA Conf. Pub. 2185, DOE Pub. CONF-810226, Cleveland, OH, (1981).

Currin, H. "North Wind 4kW 'Passive' Control System Design," Proc. Wind Turbine Dynamics, NASA Pub. 2185, DOE Pub. CONF-810226, Cleveland, OH, (1981).

Hohenemser, K. H. and Swift, A. H. P. "Dynamics of an Experimental Two Bladed Horizontal Axis Wind Turbine with Blade Cyclic Pitch Variation," Wind Turbine Dynamics, NASA Pub. 2185, DOE Pub. CONF-810226, Cleveland, $\mathrm{OH},(1981)$.

Karaolis, N. M., Mussgrove, P. J., and Jeronimidis, G. "Active and Passive Aeroelastic Power Control using Asymmetric Fibre Reinforced Laminates for Wind Turbine Blades," Proc. 10th British Wind Energy Conf., D. J. Milbrow Ed., London, (1988).
Karaolis, N. M., Jeronimidis, G., and Mussgrove, P. J. "Composite Wind Turbine Blades: Coupling Effects and Rotor Aerodynamic Performance," Proc., EWEC'89, European Wind Energy Conf., Glasgow, Scotland, (1989).

Stoddard, F., Nelson, V., Starcher, K., Andrews, B. "Determination of Elastic Twist in Horizontal Axis Wind Turbines," AEI, West Texas State Univ., SERI Cntr. RL-6-06013, NREL, Golden, CO, (1989).

Corbet, D. C. and Morgan, C. A. "Report on the Passive Control of Horizontal Axis Wind Turbines," ETSU WN 6043, Garrad Hassan and Partners, Bristol, UK, (1992).

Kooijman, H. J. T. "Bending-Torsion Coupling of a Wind Turbine Rotor Blade," ECN-I--96-060, Netherlands Energy Research Foundation ECN, (1996).

Windpower Monthly February Windtech Notes, compiled by D. Milborrow, pp. 42-43, (1998).

\section{Helicopter Applications}

.McCarthy, J. L., and Brooks, G. W., "A Dynamic Model Study of the Effect of Added Weights and Other Structural Variations on the Blade Bending Strains of an Experimental Two-Blade Jet-Driven Helicopter in Hovering and Forward Flight," NACA TN-3367, (1955).

Miller, R.H., and Ellis, C.W. "Helicopter Blade Vibration and Flutter," Journal of the American Helicopter Society, Vol. 1, No. 3, pp. 19-38, (1956).

Hirch, H., Dutton, R. E., and Rasamoff, A. "Effects of Spanwise and Chordwise Mass Distribution on Rotor Blade Cyclic Stresses," Journal of the AHS, Vol. 1, No. 2, pp. 37-45, (1956).

Daughaday, H., DuWaldt, F., and Gates, C. "Investigation of Helicopter Blade Flutter and Load Amplification Problem," J. of the American Helicopter Soc., Vol. 2, No. 3, pp. 27-45, (1957).

Shanthakumaran, P. "Optimum Design of Rotor Blades for Vibration Reduction in Forward Flight," Ph.D. Dissertation, Mechanics and Structures Dept. UCLA, (1982).

Blackwell, R. H. "Blade Design for Reduced Helicopter Vibration," Joumal of the American Helicopter Society, Vol. 28, No. 3, pp. 33-41, (1983).

Friedmann, P. P., and Shanthakumaran, P. "Aeroelastic Tailoring of Rotor Blades for Vibration Reduction in Forward Flight," AIAA Paper 83-0916, (1983).

Friedmann, P. P., and Shanthakumaran, P. "Optimum Design of Rotor Blades for Vibration Reduction in Forward Flight," Journal of the AHS, Vol. 29, No. 4, pp. 7080, (1984). 
Hong, C.H., and Chopra, I. "Aeroelastic Stability of a Composite Blade," Joumal of the AHS, Vol. 30, No. 2 , (1985).

Panda, B., and Chopra, I. "Dynamics of Composite Rotor Blades in Forward Flight," Vertica, Vol. 11, No. 1-2, (1987).

Celi, R. "Aeroelasticity and Structural Optimization of Helicopter Rotor Blades with Swept Tips," Ph.D. Dissertation, Mechanical, Aerospace and Nuclear Engineering Dept., UCLA, (1987).

Lim, J., and Chopra, I. "Design Sensitivity Analysis for an Aeroelastic Optimization of a Helicopter Rotor," AIAA Paper 87-0923, (1987).

Lim, J., and Chopra, I. "Aeroelastic Optimization of a Helicopter Rotor," Proc., 44 ${ }^{\text {th }}$ Annual Forum of the AHS, Washington DC, pp. 545-558, (1988).

Celi, R., and Friedman, P. P. "Structural Optimization with Aeroelastic Constraints of Rotor Blades with Straight and Swept Tips," AIAA Paper 88-2297; also, AIAA Journal, Vol. 28, No.5, (1988).

Bir, G., Chopra, I., Nguyen, K. "Development of UMARC (University of Maryland Advanced Rotor Code)," Proc. of the $46^{\text {th }}$ Annual National Forum of the $A H S$, Washington, D.C., (1990).

Smith, E. C., and Chopra, I. "Formulation and Evaluation of an Analytical Model for Composite Box Beams," Journal of the American Helicopter Society, (1991).

Chandra, R., and Chopra, I. "Experimental and Theoretical Analysis of Composite I-Beams with Elastic Couplings," AIAA Journal, Vol. 29, No. 12, (1991).

Chandra, R., and Chopra, I. "Structural Behavior of Two-Cell Composite Rotor Blades with Elastic Couplings," AIAA Journal, Vol. 30, No. 12, (1992).

Ganguli, R., and Chopra, I. "Aeroelastic Optimization of a Composite Helicopter Rotor," Fourth AIAA Symposium on Multidisciplinary Analysis and Optimizations, Cleveland, Ohio, (1992).

Ganguli, R., and Chopra, I. "Aeroelastic Optimization a Helicopter Rotor with Composite Tailoring," Proceedings of the $49^{\text {th }}$ Annual Forum and Technology Display of the American Helicopter Society, St. Louis, Missouri, (1993).

Bir, G., and Chopra, I. "Aeroelastic Stability of Rotorcraft with Advanced Geometry Blades," Mathematical and Conip. Modeling, Vol. 19, No. 34, (1994).

Ganguli, R., and Chopra, I. "Multi-Objective Optimization of a Composite Helicopter Rotor," Presented at the $35^{\text {th }}$ Structures, Structural Dynamics and Materials
Conference and Adaptive Structures Forum, (1994).

Ganguli, R., and Chopra, I. "Aeroelastic Tailoring of Composite Couplings and Blade Geometry of a Helicopter Rotor Using Optimization Methods," Journal of the AHS, Vol. 42, No. 3, (1997).

\section{REFERENCES}

1. P. S. Veers, G. Bir and D. W. Lobitz, "Aeroelastic Tailoring in Wind-Turbine Blade Applications," Proc. Windpower '98, AWEA Annual Conference and Exhibition, Bakersfield, Apr. 27 - May 1, 1998.

2. D. W. Lobitz, P. S. Veers and P. G. Migliore, "Enhanced Performance of HAWTs Using Adaptive Blades," Proc. Wind Energy '96, ASME Wind Energy Symposium, Houston, Jan. 29 - Feb. 2, 1996.

3. D. W. Lobitz, and P. S. Veers, "Aeroelastic Behavior of Twist-Coupled HAWT Blades," Proceedings of the 1998 ASME Wind Energy Symposium, Reno, January 12-15, 1998.

4. D. W. Lobitz and D. J. Laino, "Load Mitigation with Twist-Coupled HAWT Blades," Proceedings of the 1999 ASME Wind Energy Symposium, Reno, January 11-14, 1999.

5. ADAMS/SOLVER Reference Manual, Version 9.1, Mechanical Dynamics, Inc., Ann Arbor, 1998.

6. C. H. Ong, J. Wang and S. W. Tsai, "Design, Manufacture and Testing of a Bend-Twist D-Spar," Proceedings of the 1999 ASME Wind Energy Symposium, Reno, January 11-14, 1999.

7. ADAMS/WT User's Guide, Version 2.0, Mechanical Dynamics, Inc., Ann Arbor, December, 1998.

8. N. D. Kelley, "Full-Vector (3-D) Inflow Simulation in Natural and Wind Farm Environments Using an Expanded Version of the SNLWIND (Veers) Turbulence Code," Proceedings of the 12th ASME Wind Energy Symposium, Houston, 1993.

9. Safety of Wind Turbine Generator Systems, International Electrotechnical Commission, IEC 614001, Second Edition, 1998.

10. A. C. Hansen, Aerodvn for ADAMS User's Guide, Version 11.0, University of Utah, Salt Lake City, August 31, 1998. 